\title{
The End of a Centralized Open Access Project and the Beginning of a Community-Based Sustainable Infrastructure for Latin America: Redalyc.org after Fifteen Years
}

\author{
Arianna Becerril-García and Eduardo Aguado-López
}

\section{The Open Access ecosystem in Latin America}

1 Despite the fact that Open Access (OA) is a worldwide reality; it is a fact taking different shades and intensities with asymmetrical regional impacts.

2 Latin America has created and maintains a non-commercial structure where scientific publication belongs to the academy and not to large publishers; where the Open Journal Systems software has been key in the birth of the electronic journal; where the need for visibility, interoperability and presence on the web was the breeding ground for the emergence of platforms such as Latindex, Redalyc and Scielo. This region has an ecosystem where the nature of publication is conceived as the act of making public, of sharing and not as the publishing industry.

3 Neither a fee for authors nor a fee for readers had been included in the regional editorial tradition. If a fee existed were definitely for non-profit, as a journal business model commonly lay on an institutional budget.

4 One key feature it is worth looking at from Latin America is that publishing is led, owned and financed scholarly, it is not common to outsource editorial processes.

5 Each institution is part of an informal cooperative that has not ever been made explicit; but every institution finances journals with its own faculty members, and then that content is made available through open access to other institutions. Which means that 
everybody gets benefit from everybody else's investment. This kind of informal cooperative has really worked even before Open Access got its name.

Regarding green open access, the region counts on different initiatives as the growing quantity of institutional repositories that reaches currently 362 (OpenDOAR, 2018). For its part, LaReferencia, the network of national networks of institutional repositories integrates, through metadata harvesting, more than 1.3 million documents.

7 Latin America have also legislated on Open Access such are the cases of Peru, Argentina and Mexico national policies along with institutional mandates giving a total of 48 (ROARMAP, 2018). However, as it is pointed out by Babini (2014) institutional mandates are weak.

8 There are also disciplinary repositories like the one of CLACSO, specialized in Social Sciences, SIDALC in Agriculture, CLAD in Public Administration, LaborDoc in Labour, BVSDE in Enviromental Health and the BVS in Health.

9 From our perspective, there are many strengths but also important threats that are already molding different aspects of how OA is evolving in Latin America. The illustration below shows a SWOT analysis to summarize main ideas.

10 A crucial weakness is that the majority of assessment systems have been simplified and the importance of a journal depends on the JCR classification of Clarivate Analytics or Elsevier's Scopus, no matter the scientific conversation that is taken place inside the journal or the local or regional problems being solved or discussed. This method, although it is to classify scientific journals, also impacts researchers since their incentives depend on where they publish. Such is the case of Colombia, that in 2017 eliminated more than $40 \%$ of its publications from Publindex, a national index.

11 Most Colombian as well as Latin American journals are published in universities by the educational sector, and as a consequence of those decisions they are receiving less and less resources each day starting to cause a devastating disappearance of journals which are not indexed by JCR or Scopus ignoring the journal contribution to science and society. The same situation applies to Redalyc, as it is an index that is out of what is considered as the status quo in research assessment systems, its financial supporters start to question about the feasibility to continue investing in this project leaving out the ten million article downloads per month or the 54 thousand of users accessing to Redalyc per day. That problem along with the lack of editors' leadership and the researchers' carefree attitude with minimal response to research assessment policies put at risk the legitimation of both regional and Open Access initiatives that could function as a counterweight for the continue local knowledge generation. 


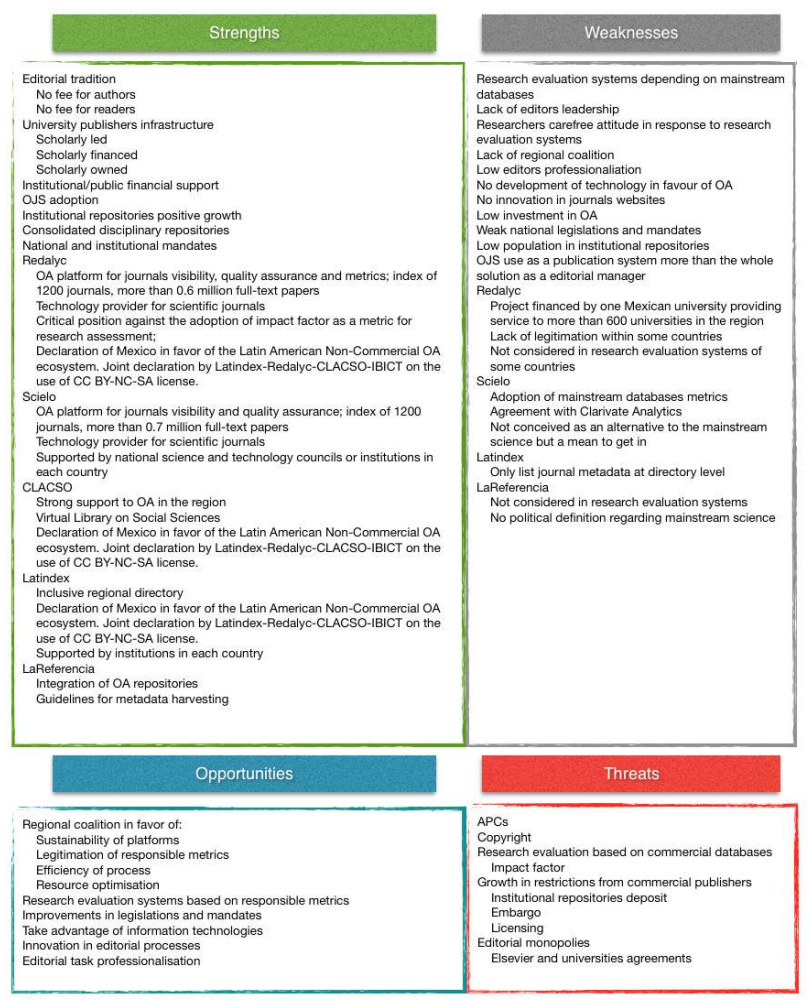

14 Scheliga and Friesike (2014) analyze the fact that while many researchers support open science in theory, the individual researcher is confronted with various difficulties when putting open science into practice, they argue that the phenomenon of open science can be seen through the prism of a social dilemma: what is in the collective best interest of the scientific community is not necessarily in the best interest of the individual scientist.

15 As it is said in DORA (2012) "The outputs from scientific research are many and varied, including: research articles reporting new knowledge, data, reagents, and software; intellectual property; and highly trained young scientists. Funding agencies, institutions that employ scientists, and scientists themselves, all have a desire, and need, to assess the quality and impact of scientific outputs. It is thus imperative that scientific output is measured accurately and evaluated wisely."

16 Another circumstance to bring to the analysis, is the lack of innovation, professionalization and development of technology in the editorial work of the region, condition that evidence the need of a better optimization of resources in benefit of Open Access and science, instead of isolated efforts in the matter of technology in each institution.

An interesting phenomenon in course in Latin America has to do with the consolidated OA platforms, which are taking different paths and directions, preventing a strategic regional coalition to be built. Such is the case of Scielo, which opted to look towards Clarivate Analytics in order to create a journal citation index inside Web of Science (out of the core collection), a strategy to be the mean to reach the inclusion of journals in the mainstream science; while Redalyc seeks to strengthen publishers inside universities by empowering editors with technology and training and providing a set of metrics that shows different aspects of the science performance rather than impact based on citations. 
Redalyc's vision is more aligned with Curry (2017) that argues that it's time for academics to take back control of research journals and that the evolution into a highly-profitable industry was never planned. Academics must make the case for lower-cost journals.

Apart from that, there are some "external" phenomena affecting the non-commercial nature of the Latin American ecosystem. After the formalization of the Open Access movement through the three statements: Budapest (Chan, y otros, 2002), Berlin (Max Planck Society, 2003), and Bethesda (Brown, y otros, 2003); the Global North started to transform its editorial practices, mainly focus on commercial publishing, to achieve OA. Those changes caused the relocation of costs, from readers to authors with the so-called Article Processing Charges or APCs. The big four players in the publishing industry, e.g., Elsevier, Springer, Wiley and Taylor \& Francis, have all embraced OA, albeit to varying degrees. They have also employed highly different strategies as to how much they would like to charge their authors (Beata, 2017). difficulty for a Latin-American author to publish. Besides, as it was said in (Katie, 2016): the number of article processing charges paid doubled between 2013 and 2014. The average APC increased by $6 \%$ in those years, a rise well above the cost of inflation. Publishers' APC costs are converging to a more uniform price range, although they still vary widely. Journals with low APCs are raising their prices, perhaps to avoid being perceived as low quality following expectations set by the Finch report (Finch, 2012).

As the asymmetries between the "commercial" and the "open" are extended, the corporations impose rules that restrict access to knowledge in multiple ways. The paper in Elizabeth \& Denise (2016) demonstrated it by analyzing the Sherpa/ROMEO database: "Just as there is an upward trend among these 107 publishers in the number of publishers allowing some form of self-archiving, there is also a year-on-year rise in the number of restrictions and conditions constraining the right to self-archive and the offer of paid open access options... Restrictions around when a paper may be self-archived grew $1000 \%$... Restrictions relating to where a paper may be archived were even more prevalent and followed a similar growth pattern of $190 \%$."

This work describes the first Redalyc's model that led the project to achieve its original goals, presents the problematic is facing and the new business model Redalyc is designing and adopting to operate on. A new configuration of strategies, in response to the international, regional, national and institutional context, that seeks a collaborative, sustainable, protected and non-commercial Open Access solution for Latin America.

\section{Redalyc as a centralized OA project}

Redalyc begun in 2003 with the main goal of contributing to the visibility of scientific journals published in the region. In a time where the majority of them didn't even appear on the Web. It started indexing only journals of Social Sciences and Humanities and in 2006 included all areas of knowledge due to a high demand from editors.

Today Redalyc's collection contains more than a half million full-text articles from 1.260 Open Access peer-reviewed journals published by 622 publishers from 22 countries of Latin America, Spain and Portugal.

5 The following diagram shows the Redalyc infrastructure. Each layer presents different added-value services that Redalyc provides to journals with the aim of complementing 
the features and capabilities the editors are able to achieve. It is important to highlight that in other regions of the world there are commercial publishers in charge of providing this kind of services.

Redalyc architecture
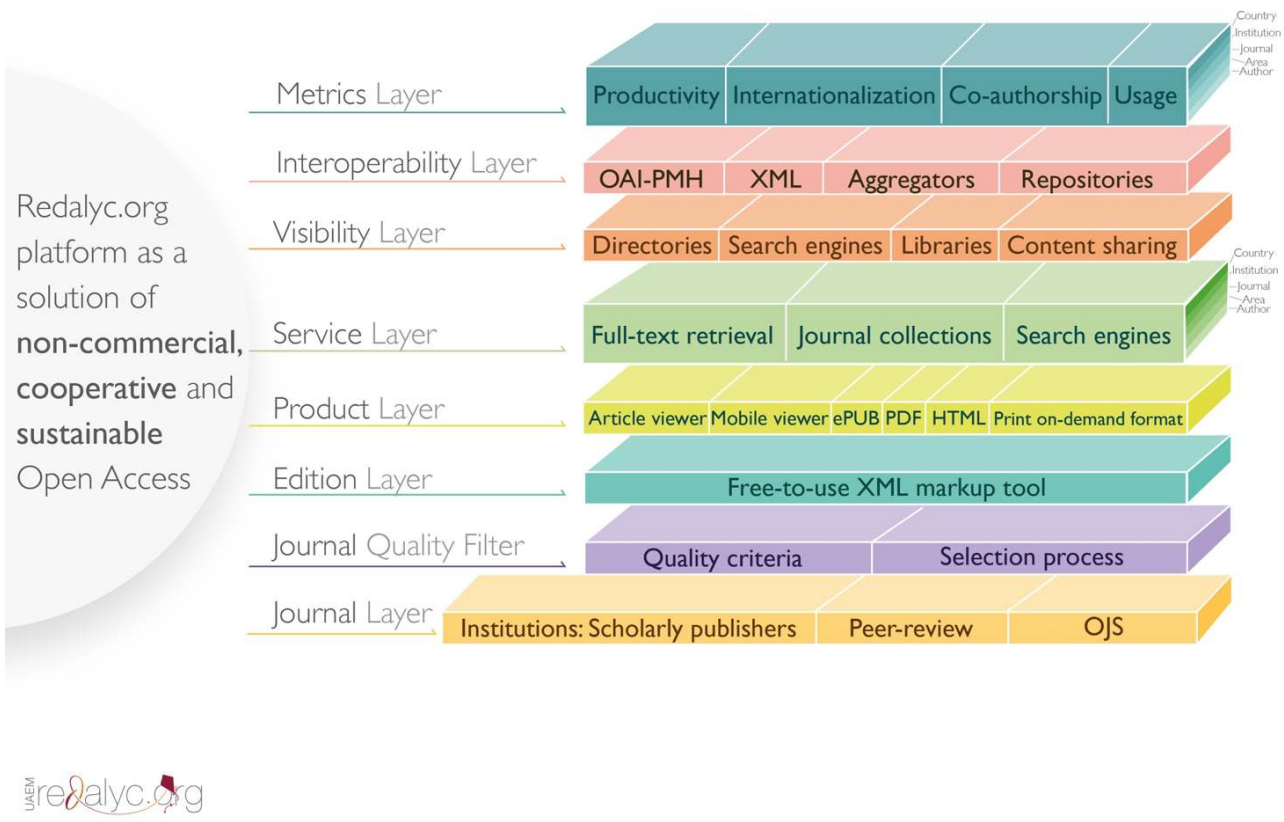

On the base of the structure shown there are peer-reviewed journals along with its publisher institutions who sign an agreement with Redalyc in order to allow the electronic distribution of metadata and the publication online of the full-text articles.

For a journal to be indexed in Redalyc must pass a rigorous selection process based on quality criteria (Redalyc, 2018) including among other mandatory requirements to carry a peer review process and to publish at least $75 \%$ of original content, joint with criteria like exogeneity of referees and editorial board, efficiency of editorial processes, editorial, visibility and technological practices, periodicity compliance, etc. After getting an internal result the International Advisory Board, which is composed by experts from diverse fields and different countries, is asked for a qualitative assessment.

On the other hand Redalyc, aware that one of the highest cost in publishing electronic journals is the XML tagging and that this process is key in reaching technological standards, developed an XML markup system-called Marcalyc-in order to contribute to the sustainability of journals (Redalyc, 2016).

Marcalyc is based on the Journal Article Tag Suite ANSI/NISO Z39.96-2015 standard (NISO, 2015) and allows journal editors to get its articles in XML file format. Free access to this tool is provided for Open Access non-APC scholarly journals indexed by Redalyc. A tool designed to prevent editors from outsourcing XML markup; it doesn't require technical expertise and it minimizes markup time. It is also JATS4R compliant (JATS4R, 2018). 
30 Marcalyc, together with the XML file format, automatically generates a media enriched article reader and a mobile reader available in Redalyc and the PDF, ePUB and HTML versions ready to be uploaded in journal websites.

Since Marcalyc was launched in September 2016, 1.158 journal issues have been processed. In a collaborative process, Redalyc provides the tool and the journal editor do the job. Based on the average market cost of XML generation per journal issue (US\$300), that quantity of XML files would have cost approximately USD\$347,400. For each of all those articles, Redalyc also provided the PDF, ePUB, HTML and the interactive article reader versions, whose costs must be summed to the total subsidy that Redalyc is providing to journals in Latin America.

Coupled with that, there are successful cases that account for Redalyc's contribution, e.g., journal editors generating XML content with no-cost in Marcalyc, and taking them to their own websites, along with all file versions listed above; and journal editors switching from a policy of APC to a non-APC in order to apply for a Marcalyc user account.

What is more, Redalyc provides homepages not only for journals but also for countries, authors, institutions and areas of knowledge with their journals collection, search engines, advanced filters, different data visualizations and metrics.

Regarding visibility, Redalyc works with search engines, libraries, directories and social media to disseminate broadly the scientific content and to improve its discoverability. As well as with repositories and aggregators through interoperability protocols like OAIPMH.

Besides, the signed agreements between Redalyc and journals allow Redalyc to populate institutional repositories too, helping repositories to automatically integrate metadata of articles corresponding to the institutional output; for example, in the case of the National Autonomous University of Mexico UNAM, Mexico Redalyc is able to send more than 10 thousand articles at metadata level to the institutional repository at UNAM.

In different dimensions that is the case of more than 10 thousand institutions which have research output published in the journals indexed by Redalyc that can take advantage of Redalyc's database to populate their repositories.

The same happens with the scientific output at a country-level as shown below, data which can be used to strengthen national repositories.

Scientific output by country available in Redalyc

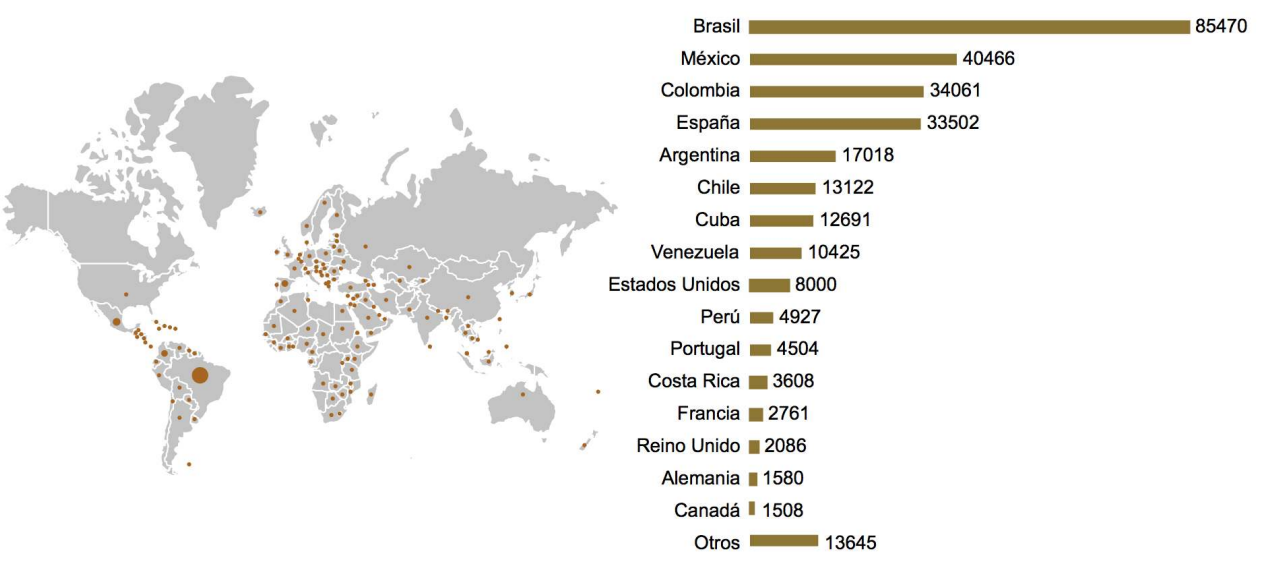



other stakeholders rather than rely only on the Autonomous University of the State of Mexico, who has supported Redalyc since its beginning but who is aware that Redalyc's current reach exceeds the university's capacity. It is important to recognize that a project with that regional scope must not depend on a single actor in order to guarantee longterm sustainability.

These circumstances have led to a redefinition of a project-Redalyc.org-that begun in 2003 and that has already fulfilled its original mission: give visibility to knowledge generated in Latin America and promote quality of scholarly journals. Nevertheless, it is mandatory to be transformed from a Latin American platform based in Mexico into a community-based regional infrastructure that continues assessing journals quality and providing access to full-text articles but taking into consideration individual journals' efforts in benefit of journals positioning and visibility. A framework that generates technology in favor of the empowerment and professionalization of journal editors, making the editorial task in open access sustainable and that allows Redalyc to sustain itself collectively.

\section{The next Redalyc, a community-based sustainable infrastructure for Latin America}

It is necessary not only to refine critical positions to face the global context of OA, but to design and put into practice collaborative systems that develop and socialize technology and know how in scientific communication. 
The goal is to build and sustain a collaborative infrastructure to develop technology and generate knowledge in order to strengthen and protect the scientific editorial work and its actors, a framework that can be extended to include the Global South, with a special emphasis on Social Sciences and Humanities. All this to achieve a non-subordinate integration of this region into the global dialogue of scientific communication.

This is aligned with the vision in Rob (2015), where it is said that "we should work towards simplifying and standardizing processes to move towards a sustainable and scalable OA ecosystem which preserves academic freedom and author choice in publishing and makes the research as valuable as possible for the end user".

The new strategy consists of forming an alliance of institutions that are willing to maintain the non-commercial nature of the Latin American ecosystem and keep supporting scientific publications that contribute to the benefit of society and the development of science, regardless of whether they are indexed in the so-called mainstream science or which impact factor is assigned to it.

48 The participating institutions should share the following DORA declaration themes (DORA, 2012):

- the need to eliminate the use of journal-based metrics, such as Journal Impact Factors, in funding, appointment, and promotion considerations;

- the need to assess research on its own merits rather than on the basis of the journal in which the research is published; and

- the need to capitalize on the opportunities provided by online publication (such as relaxing unnecessary limits on the number of words, figures, and references in articles, and exploring new indicators of significance and impact).

In order to achieve this transformation, the most relevant tasks that have been established are:

- recognize Redalyc as an inclusive journal indexing system that contributes to the strengthening of quality of scientific journals published in the region;

- develop and adopt a set of responsible metrics for the assessment of scientific performance that takes into account the contribution to the field of knowledge and to society. This task includes the selection of the most suitable metrics already developed by the stakeholders or perhaps develop new ones;

- develop and sustain a digital edition tool that enables collaborative paper XML tagging under JATS metadata standard that provides regional publishers the possibility of being at the forefront of technology at minimal cost -when the editorial team do the job by themselves- or at fair prices when there is a need to outsource the process;

- develop technology and provide knowledge transference for tasks such as digital preservation of scientific content, visibility, interoperability, discoverability, among others;

- develop technology for the optimization of editorial processes through the promotion of the formation of a developers' community in order to take better advantage of the OJS;

- build a blog as a mean of critical discussion on scientific communication and its particular problems in the Global South: challenges, actors, trends, news, advances, reviews and proposals.

The institutions that up to now have expressed their interest in being part of this model are University of La Plata, Argentina; University of Antioquia, Colombia; CLACSO, Argentina; University Corporation for Internet 2, CUDI, Mexico; Autonomous University of Chiapas, Mexico, among others. 
51 Some of those institutions are also intended to contribute with computing power, software developers and high speed connectivity to enhance the service for users and continue developing innovative solutions.

The new constitution that Redalyc will adopt is based on these fundamental principles:

1. Scientific knowledge generated with public funds is a common good and access to it is a right. Therefore, it must be available in Open Access. We recognize that Open Access has been used as a tool for the benefit of large publishing consortiums, it is an unwanted effect of the movement that must be controlled.

2. Open Access can only be consolidated if it is legally protected. The Open Access mandates and laws and the use of Creative Commons BY-NC (Non-Commercial Attribution) licenses, and desirable SA (Share Alike), are fundamental protection strategies, which are aimed at not allowing the appropriation of scientific knowledge for profit.

3. Open Access has no future or meaning without an evolution of research evaluation systems: if we recognize the value of Open Access as an appropriate channel of communication, it must be recognized as a legitimate way from which to evaluate the scientific and scholar practices.

4. The consolidation of Open Access must consider the transition to digital scientific communication as an essential axis. In this sense, the development and adoption of technologies that allows to think about new communication possibilities to increase the essential objective of science: communication.

5. The economical investment in Open Access must be coherent with its benefit to society just as commercial solutions are paid. In Latin America, governments, science and technology councils, institutions and libraries hardly invest in Open Access compared to increasingly high prices paid to commercial services.

6. The adverse economic scenarios facing Open Access in Latin America will have to be overcome with work schemes based on collaboration and sustainability; likewise, through a permanent disposition to dialogue with science and technology councils, governments, universities, international organizations and all actors with a shared vision of this movement.

7. It is necessary to recognize the diversity of scientific journals and stop the pressures that seek to homogenize them, from language to research agendas. It is necessary to vindicate the relevance of local, or national and regional issues in journals; as well as the articulation with the needs of the development and quality of life of society. In turn, it is necessary that journals support the strengthening of institutional repositories by means of the disappearance of policies of embargo of scientific articles or retention of author rights that prevent their deposit.

8. The sustainability of Open Access is the conviction that science can and should have a central role in the development of societies. The social impact of science is the foundation of its existence.

9. The different areas of knowledge have different dynamics of generation and circulation of knowledge. It is necessary to respect the different idiosyncrasies by area, especially the dynamics of the Social Sciences and the Humanities, as well as their different communication formats.

10. Open Access must be permanently conceptualized and defined according to the contexts it faces; this is an imperative that arises when observing the context in which the statements of Budapest, Bethesda and Berlin emerged is different from the current one. The three "B" homogenize the conditions of development of science and the conditions of the South are different from those of the North. 

commissions are proposed

- Technological development

- Research

- Editorial processes

- Continuous training

- Responsible metrics

- Observatory of scientific evaluation

- Open Data

- Repositories

- Copyright

\section{Conclusions}

57 It is necessary to think of Open Access from Latin America but also from the Global South perspective, recognizing its experience and leadership in the defense and contribution to the movement. In turn, it is necessary to think of the Global South not only as a geographical region, but as a shared historical past and as a possibility of future construction. Thus, the defense of Open Access will also be a defense for the memory, justice, truth and development of people.

58 The future of academic publication in our region must be a commitment of its actors, as well as a collective right that must be actively, intelligently and creatively claimed.

\section{BIBLIOGRAPHY}




\section{References}

Beata, S. (2017, April). How Much Do Top Publishers Charge for Open Access? Retrieved from http:// openscience.com/how-much-do-top-publishers-charge-for-open-access/

Brown, P., Cabell, D., Chakravarti, A., Cohen, B., Delamothe, T., Eisen, M., et al. (2003). Declaración de Bethesda sobre Publicación de Acceso Abierto. Retrieved from http://ictlogy.net/articles/ bethesda_es.html

Chan, L., Cuplinskas, D., Eisen, M., Friend, F., Genova, Y., Guédon, J.-C., et al. (2002). Budapest Open Access Initiative. Retrieved from http://www.soros.org/openaccess/read.shtml

Elizabeth, G., \& Denise, T. C. (2016). What does 'green' open access mean? Tracking twelve years of changes to journal publisher self- archiving policies. (C. M. University, Ed.)

Finch, D. J. (2012). Accessibility, sustainability, excellence: how to expand access to research publications. Report of the Working Group on Expanding Access to Published Research Findings.

JATS4R. (2018). Jats for Reuse. Retrieved from https://jats4r.org

Katie, S. (2016, June). Article processing charges (APCs) and subscriptions. Monitoring open access costs. Retrieved from https://www.jisc.ac.uk/reports/apcs-and-subscriptions

Max Planck Society. (2003). Berlin Declaration on Open Access to Knowledge in the Sciences and Humanities. Retrieved from http://openaccess.mpg.de/Berlin-Declaration

NISO. (2015). JATS: Journal Article Tag Suite, ANSI/NISO Z39.96-2015. Retrieved from http:// jats.niso.org/1.1

Redalyc. (2016). Marcalyc. Retrieved March 3, 2018, from XML JATS markup system: http:// marcalyc.redalyc.org

Redalyc. (2018). Redalyc selection criteria. Retrieved from http://www.redalyc.org/redalyc/ editores/criterios.html

Rob, J. (2015). Making open access work for authors, institutions and publishers. A Report on an Open Access Roundtable Hosted by Copyright Clearance Center, Inc. Retrieved from http:// www.copyright.com/content/dam/cc3/marketing/documents/pdfs/Report-Making-OpenAccess-Work.pdf

\section{ABSTRACTS}

The Latin American region has an ecosystem where the nature of publication is conceived as the act of making public, of sharing and not as the publishing industry. International, national and institutional contexts have led to a redefinition of a project-Redalyc.org-that begun in 2003 and that has already fulfilled its original mission: give visibility to knowledge generated in Latin America and promote quality of scientific journals. Nevertheless, it is mandatory to be transformed from a Latin American platform based in Mexico into a community-based regional infrastructure that continues assessing journals quality and providing access to full-text in benefit of journals visibility and free access to knowledge. A framework that generates technology in favor of the empowerment and professionalization of journal editors, making the editorial task in open access sustainable and that allows Redalyc to sustain itself collectively. This work describes the first Redalyc's model, presents the problematic in course and the new business model Redalyc is designing and adopting to operate on. 
INDEX

Keywords: Redalyc, Open Access, Latin America

\section{AUTHORS}

\section{ARIANNA BECERRIL-GARCÍA}

Autonomous University of the State of Mexico, Mexico

arianna.becerril@gmail.com

http://www.redalyc.org/redalyc/media/redalyc_n/Estaticas3/curriculum/ariannaCV.html (corresponding author)

\section{EDUARDO AGUADO-LÓPEZ}

Autonomous University of the State of Mexico, Mexico

eal123@gmail.com

http://www.redalyc.org/redalyc/media/redalyc_n/Estaticas3/curriculum/eduardoCV.html 